\title{
Golpes de Memória: usos políticos de Olavo Bilac no século XX ${ }^{\mathrm{I}}$
}

\author{
[ Coups of Memory: Political Usages of Olavo Bilac \\ in the Course of the 2oth Century
}

\section{Patrícia Santos Hansen²}

RESUMO Este trabalho tem como objetivo expor em, linhas gerais o processo de enquadramento político da memória do poeta Olavo Bilac ao longo do século XX no Brasil. Começo com o esboço de uma imagem de si que Bilac tentou legar à sua audiência em textos, palestras e atos públicos na maturidade, fortemente associada ao engajamento na campanha cívica em prol do serviço militar obrigatório. Em seguida, enfoco as apropriações mais importantes das suas ideias e de sua imagem, ressaltando especialmente os sentidos sobrepostos por indivíduos e grupos de orientações políticas diversas em momentoschave da história política brasileira no século $\mathrm{XX}$. Por fim, procuro ressaltar alguns desvios em relação às posições assumidas nos últimos esforços de autorrepresentação de Bilac enquanto homem público, provocados pelos significados adicionados à sua imagem em outros contextos. - Palavras-Chave Olavo Bilac; Memória Social; Ditadura; Serviço Militar; Usos do Pas- sado. - ABSTRACT This paper aims to provide an overview of political operations that framed the social memory of famous Brazilian poet Olavo Bilac over the 2oth century. It will start by showing an image that Bilac sought to bequeath to his audience through his last texts, talks and public acts, strongly associated with his engagement in the civic campaign for compulsory military service. Subsequently, the focus will be on the most meaningful appropriations of his thinking and opinions in order to examine the overlapped senses that persons and groups from a broad range of ideological positions ascribed to them at critical moments of Brazilian political history in the 2oth century. Finally, some of the convergences and discrepancies between major components of Bilac's late endeavors of selfrepresentation and those assigned to him in subsequent times will be analyzed - KEYwords Olavo Bilac; Social Memory; Dictatorship; Military Service; Uses of the Past.

Recebido em I3 de outubro de 2014

Aprovado em 05 de dezembro de 2014

hansen, Patrícia Santos. Golpes de Memória: usos políticos de Olavo Bilac no século XX. Revista do Instituto de Estudos Brasileiros, Brasil, n. 6I, p. I22-I39, ago. 2015.

DoI: http://dx.doi.org/Io.II606/issn.23I6-90IX.voi6IpI22-I39

I A pesquisa e a escrita deste artigo foram possibilitadas pelo apoio financeiro da Capes/FAPERJ no Brasil e da FCT em Portugal, em diferentes momentos. Agradeço com carinho à Angela de Castro Gomes, minha supervisora no pós-doutorado realizado entre 20Io e 20II, no CPDOC/FGV, sobre o nacionalismo bilaqueano, pela amizade e interlocução que ultrapassam em muito esse período. Agradeço também a Rafael Guerra, pela leitura do rascunho e por muito mais. Registro também o meu agradecimento aos pareceristas anônimos da Revista do IEB pelos comentários ao texto submetido. Este artigo é dedicado à memória do brilhante Nicolau Sevcenko, meu saudoso orientador, falecido prematuramente em 20I4.

2 Instituto de Ciências Sociais da Universidade de Lisboa (ICS, Lisboa, Portugal) 
Em abril de I966, o General Castello Branco, então presidente da república, assinou um decreto que instituía Olavo Bilac patrono do serviço militar, baseando-se nos seguintes argumentos para fazer do famoso poeta o primeiro patrono civil das Forças Armadas Brasileiras:

— que Olavo Bilac foi o grande propugnador do Serviço Militar obrigatório, em favor de cuja adoção empreendeu uma campanha de âmbito nacional nos anos de I9I5 e I9I6; — que seus poemas, a letra do Hino da Bandeira e seus discursos vibrantes constituem o catecismo cívico da juventude brasileira;

- que o sentimento do dever cívico se inspira nos momentos em que a Pátria tem a oportunidade de rememorar os seus vultos maiores, buscando em suas atitudes exemplos para as novas gerações, [.....$^{\mathrm{I}}$

As razões apresentadas no decreto encontram suas origens em um acontecimento específico ocorrido a 9 de outubro de I9I5. Neste dia, por convite do Centro Acadêmico XI de Agosto da Faculdade de Direito de São Paulo, Bilac fez um discurso dirigido aos estudantes da prestigiosa instituição, que acabou por ser assumido e referido pelas gerações posteriores como um evento marcante e significativo, atribuindo-se-lhe o efeito de despertar um súbito sentimento patriótico entre segmentos letrados e formadores de opinião e de provocar rápida mobilização cívica.

Aquele "ato de fala" singular, extraordinário por sua repercussão imediata e duradoura, deu origem a muitos outros, os quais por sua vez ressoaram em outras ações de significativo impacto na memória, na história e na cultura política brasileira ao longo do século $\mathrm{XX}^{2}$.

Além do destaque nos jornais e revistas e dos convites que logo vieram para um banquete em sua homenagem oferecido pelo Exército no Clube Militar e para um

I DECRETO No 58.222, de I9 de abril de I966. Disponível em 〈http://goo.gl/VUIIF3〉. 5 mar. 2014.

2 Apesar de não aprofundar o tema, sublinho a importância de pensar os discursos a partir da categoria deato de fala, filiada à teoria fundada por J. L. Austin em meados do século XX e posteriormente desenvolvida por outros autores. Sublinho o uso que faço da categoria ato de fala, filiada à teoria fundada por J. L. Austin em meados do século XX. Para uma perspectiva geral da teoria dos atos de fala conferir: SOUZA FILHO, Danilo Marcondes de. A teoria dos atos de fala como concepção pragmática de linguagem, Filosofia Unisinos, n. 7, p. 2I7-230, 2006. 
discurso na solenidade da festa da bandeira promovida pela Marinha nos dias $6 \mathrm{e}$ I9 de novembro do mesmo ano, movimentações de diferentes atores individuais e coletivos na capital e em São Paulo deram origem a duas associações fundadas no ano seguinte: a Liga da Defesa Nacional e a Liga Nacionalista de São Paulo.

Na simbólica data de 7 de setembro de I9I6, foi fundada a Liga da Defesa Nacional no Rio de Janeiro, em reunião realizada na Biblioteca Nacional. A determinação gravada nos estatutos, de que o presidente da república em exercício seria sempre o presidente da Liga, reforçava o caráter apartidário do qual se pretendia revestir.

Em I6 de dezembro, o jornal O Estado de São Paulo noticiava que estavam aprovadas as bases e linhas gerais da organização de uma Liga Nacionalista por parte de alunos e ex-alunos da Faculdade de Direito3.

Apesar das duas agremiações cívicas terem alegadamente, as suas raízes fincadas naquele mesmo discurso, Bilac comprometer-se-ia de forma diferente com cada uma delas.

Na Liga da Defesa Nacional, ele trabalhou como secretário geral e foi o principal porta-voz do programa da instituição, representando-a em diversas cidades e divulgando suas propostas por meio de discursos sempre prestigiados pela presença de autoridades locais e ampla cobertura da imprensa.

Da Liga Nacionalista, Bilac foi presidente honorário, mais uma distinção mais do que um cargo propriamente dito.

Nesse sentido, importa ressaltar o vínculo mais estreito de Bilac com a Liga da Defesa Nacional e as evidências de que ele subscrevia as prioridades desta, embora se deva também sublinhar que ambas as ligas apropriaram-se das palavras proferidas no discurso da Faculdade de Direito, sempre identificado como marco simbólico e fundador das duas agremiações.

O tempo decorrido entre o discurso aos alunos da Faculdade de Direito, em outubro de I9I5, e sua morte, em dezembro de I9I8, foi o período em que Bilac mais ativamente contribuiu para a construção de sua própria imagem enquanto patriota, engajando-se intensamente na propaganda das ideias e soluções que entendia necessárias para combater os principais problemas do país. A complexidade desse processo não deve ser subestimada, considerando que, em I9I5, Bilac já desfrutava de invulgar celebridade para os padrões da época.

Bilac obteve grande sucesso literário e fama prematura, aos vinte anos, com a primeira edição do único livro de poesias que publicou em vida. Igualmente notável, porém, é a persistência de sua fama por mais de três décadas até a sua morte aos cinquenta e três.

Na "Nota Editorial" e na "Introdução Geral" à Obra Reunida de Olavo Bilac, Alexei Bueno chama a atenção para este fenômeno, o qual em sua opinião teria maior importância maior na justificativa daquele tipo de edição que, propriamente, o valor estético/literário da obra bilaqueana. Nas palavras do organizador:

3 MEDEIROS, Valéria Antônia. Antonio de Sampaio Dória e a Modernização do Ensino em São Paulo nas Primeiras Décadas do Século XX. Tese de doutorado em História da Educação. São Paulo, Pontifícia Universidade Católica de São Paulo, 2005. Disponível em <http://goo.gl/4FdLHI〉. I5 abr. 2014. 
Poucas figuras da vida mental brasileira, no decisivo período que vai das vésperas da queda da monarquia até a segunda década do século presente, tiveram uma projeção consensual, formadora de opinião e de mentalidade, comparável à de Olavo Bilac. [...] Ao contrário, portanto, da grande maioria dos escritores seus contemporâneos [...], a presença de Olavo Bilac transcende de muito a literatura, [...] fato importante para a compreensão da popularidade e da ascendência exercida por sua obra, [...]. Nomes rigorosamente contemporâneos seus, de óbvia superioridade estética, mas só estética, não partilharam nem de uma fração ínfima de sua celebridade, [...] A fama do homem, no entanto, cujo eco nos chega até hoje, embora se funde em primeiro lugar na obra em verso, nunca se limitou a ela.

[...]

O caso Olavo Bilac, na história da poesia nacional, cobre, [...], um período de trinta anos, entre a publicação das Poesias, em I888, e a morte de seu autor, em I9I8, poucos meses após o fim da Grande Guerra e de todo um período da mentalidade ocidental. O que chamamos de caso Bilac, e que se situa na complexa fronteira estético-sociológica, é o do poeta que, em toda a história de nossa literatura, alcançou o maior prestígio e a mais alta identificação popular jamais registrada, em plena vida e por um período duradouro. ${ }^{4}$

Bilac, portanto, logrou tornar-se uma figura pública dotada de extraordinário capital simbólico, cujo uso, por ele e por outros, permitiu mobilizar forças e interesses distintos em torno de projetos políticos coerentes. De um lado, agregou conhecidos expoentes da elite liberal civilista e militares na constituição da Liga da Defesa Nacional, cuja prioridade era a implementação do serviço militar obrigatório. De outro, inspirou a criação da Liga Nacionalista, associação claramente comprometida com a agenda política da elite intelectual de São Paulo, com um ambicioso programa de reforma das práticas políticas nacionais por meio da educação, do cumprimento das normas eleitorais e da garantia da integridade do voto.

Deve-se atentar para o fato de que a articulação da imagem de Bilac a estes projetos ocorreu em vida, ou seja, quando ele ainda poderia exercer significativa influência sobre os usos do seu nome. Após sua morte, porém, o capital simbólico representado pela sua memória e ideário tornou-se material disponível às mais diversas apropriações, por interesses representados pelas já mencionadas Ligas, mas também pela Academia Brasileira de Letras, Estado Novo e Ditadura Civil-Militar, para citar apenas os mais evidentes.

Antes de I9I5, as ideias que hoje costumam ser percebidas como parte de um ideário bilaqueano apresentavam-se amorfas. É em retrospecto que se identifica a coerência das opiniões de Bilac, dispersas em crônicas e na produção para a infância durante as duas décadas anteriores. Mais ainda, até aquele momento, o capital simbólico de sua imagem pública associava-se, não exclusivamente, mas primeiramente, à poesia. Somente mais tarde, portanto, o patriotismo começaria a disputar espaço com a poesia nas representações da figura pública de Bilac, simultaneamente definindo o corpo de suas ideias 5 .

4 BUENO, Alexei. Nota Editorial e Introdução Geral. In: (ed.). Olavo Bilac. Obra Reunida. Rio de Janeiro, Editora Nova Aguilar, I996, p. 9-I0

5 É curiosa a força de sua imagem como poeta se pensarmos que Bilac publicou um único livro de poesias em 
Exemplos da fama de Bilac espalham-se nos periódicos da época. No entanto, é na propaganda de produtos comerciais que temos os melhores testemunhos de sua popularidade e credibilidade: a do xarope Bromil, publicada em vários números da revista Fon-Fon que consistia numa carta manuscrita, assinada pelo poeta, acompanhada da chamada "Olavo Bilac curou-se com o Bromil"; e a dos "Cigarros Bilac", vendidos "em carteiras que continham uma poesia e um belo retrato do grande poeta”, veiculada na revista paulista A Cigarra ${ }^{6}$.

Este uso do nome de uma figura pública como marca comercial é surpreendente naquele contexto. Não obstante, importa ressaltar que I9I6 é o ano em que se multiplicam as propagandas do Bromil e que surgem os "Cigarros Bilac", ou pelo menos a sua propaganda. Este é também o ano em que a campanha cívica é efetivamente alavancada, com grande número de discursos e viagens de Bilac, e com a mobilização de esforços para a organização das Ligas da Defesa Nacional no Rio de Janeiro e Nacionalista em São Paulo. O ano de I9I6, portanto, foi aquele em que Bilac esteve mais em evidência na mídia, ainda que por diferentes razões.

Tal coincidência permite considerar a hipótese de que o intenso uso comercial do nome e da figura de Bilac, naquele ano, seja um indicador de que o discurso aos estudantes da faculdade de Direito de São Paulo, além de ter sua eficiência potencializada pela fama e carisma do poeta, foi, em contrapartida, um fator para sua propulsão, transformando o patriotismo em aspecto de peso quase equivalente a sua atividade literária no que diz respeito a sua figura pública.

Segundo o testemunho de Francisco Pati, o discurso proferido no dia 9 de outubro de I9I5 surpreendeu uma audiência que aguardava uma palestra sobre poesia7. Ao mobilizar um tom persuasivo e doutrinário, marca de sua propaganda cívica, o poeta afirmou a intenção de dar vida e duração às suas palavras, procurando sensibilizar os estudantes para os graves problemas nacionais e necessidade de propagar algumas ideias.

Em seu diagnóstico constavam como principais problemas do país: a "falta de ideal e coesão", a "indiferença das classes cultas”, a "manutenção das camadas populares na mais bruta ignorância [...] inércia, apatia, superstição" e a sua "absoluta privação de consciência". "Nos sertões", afirmava, "os homens não são brasileiros, nem ao menos são verdadeiros homens”, e tal se devia ao analfabetismo. Para Bilac, a solução era a aplicação da lei do sorteio militar, que mesmo aprovada em I908 não havia sido efetivamente posta em prática ${ }^{8}$.

vida e aos vinte e três anos, o qual teve uma segunda edição no início dos novecentos acrescida de mais alguns poemas que se tornariam famosos. Porquanto seus poemas tenham aparecido com frequência na imprensa periódica, o contraste com o volume de suas crônicas, publicadas em vários periódicos, e com sua produção de livros escolares e infantis faz com que seja espantoso que o lastro de sua figura pública tenha sido sempre e predominantemente a poesia. Sobre sua produção jornalística conferir os três volumes de DIMAS, Antônio (org.). Bilac, o jornalista. São Paulo, EDUSP/Imprensa Oficial; Campinas, Editora Unicamp, 2006.

6 CIGARROS BILAC. A Cigarra, Anno III, n.52, I9I6. Disponível em <http://goo.gl/FJWk6Z〉. I5 abr. 20I4.

7 PATI, Francisco. O Espírito Das Arcadas. São Paulo, Associação dos Antigos Alunos da Faculdade de Direito de São Paulo, 2008. Disponível em $\leq$ http://goo.gl/Hci3Cz〉. I6 abr. 20I4.

8 BILAC, Olavo. A Defesa Nacional. Rio de Janeiro, Liga da Defesa Nacional, I9I7, p. 5 e 6. Disponível em <http://goo.gl/RsRn7m>.I6 abr. 2014 
Antecipando as críticas, que de fato surgiram após sua defesa de rigor na aplicação da lei do sorteio, Bilac afirmou desde aquele primeiro discurso e muitas vezes depois não ser e nem nunca ter sido militarista. Efetivamente, a base de seu argumento era a ideia do cidadão-soldado: "Nunca fui, não sou, nem serei um militarista. E não tenho medo de militarismo político. O melhor meio para combater a possível supremacia da casta militar é justamente a militarização de todos os civis: a estratocracia é impossível, quando todos os cidadãos são soldados”.

O discurso teve efeitos imediatos. Foi festejado pela imprensa, que passou a dar ampla cobertura à campanha, e logo muitos estudantes da Faculdade de Direito engajaram-se na causa.

Desde o primeiro momento, porém, o êxito e o efeito persuasivo daquelas palavras levantaram a suspeita de que a importância do sujeito que as enunciava fosse maior que o interesse no conteúdo do discurso. Apenas cinco dias depois, a Fon-Fon publicava o seguinte diálogo:

- Ora suponha (não é difícil) suponha que, pela primeira vez, eu lhe fale com sinceridade. [...] Mas suponha que eu lhe vou falar com sinceridade, agora, sobre o serviço militar obrigatório que o discurso do poeta Olavo Bilac pregou aos estudantes de São Paulo e que entusiasmou a população do Rio. Não lhe confiarei se acho bom nem se acho mau o serviço militar obrigatório. Confio-lhe apenas isto: se outra criatura, que não Bilac, se o senhor por exemplo, fizesse aquele discurso, as mesmas palavras não acordariam os ecos que acordaram. Portanto, não é o serviço militar que está entusiasmando, neste momento, os brasileiros, — é a atitude do poeta mais amado dos Brasileiros.

- 'Talvez...'

'O senhor não acredita? O meu amigo Homero Prates costumava dizer que a opinião pública não tem opinião. Concordo com ele. Que calor, hein?

'Insuportável'. '.0

Um dos efeitos mais evidentes do impacto mobilizador do discurso foi a descoberta pelas Forças Armadas do potencial político do carismático poeta. Ele, por sua vez, também não recusou esta aliança.

Assumindo um papel modesto, nas falas de 6 e de I9 de novembro no Clube Militar e na festa promovida pela Marinha, Bilac minimizava sua importância pessoal na campanha que começava a surgir:

A vossa generosidade exagera o préstimo do meu nome e a importância do meu trabalho. [...] Nada inventei, nada criei. [...] Acredito que o valor da minha ação nasceu unicamente de uma próspera conjuntura do tempo e do lugar, — da ocasião feliz em que foram pronunciadas as minhas palavras. [.... II

9 Idem, p. 7.

Io FON-FON, 20 de outubro de I9I5. Disponível em 〈http://goo.gl/NrhBzt >. I6 abr. $20 I 4$.

II BILAC, Olavo, A Defesa Nacional, op. cit., I9I7, p. I7 e I8. 
Contudo, se em vida o patriotismo e carisma de Bilac foram reconhecidos como um valor por diferentes instituições e grupos de interesses dentro de um variado espectro de projetos políticos, após a sua morte as homenagens por parte das instituições a que esteve ligado - a Liga da Defesa Nacional, a Liga Nacionalista e a Academia Brasileira de Letras - foram sempre descompassadas e desproporcionais. Ao menos durante as duas décadas seguintes, as instituições não se uniram em qualquer celebração, promovendo somente eventos isolados de culto à memória do poeta. Essa constatação nos permite supor que o único elemento articulador entre elas teria sido o próprio Bilac.

Contraditoriamente, a primeira instituição a mobilizar grandes recursos para homenagear o poeta foi a Liga Nacionalista, justamente aquela cujo programa acabou por ser o mais dissociado da memória sobre a atuação cívica e o ideário bilaqueano. Duas razões podem ter contribuído para isso. Por um lado, a curta existência desta liga extinta em I924 em relação à sobrevivência das outras instituições até hoje. Por outro, o investimento que os regimes autoritários fizeram, em I939 e a partir de I965, para resgatar a memória do poeta civil e defensor do serviço militar, contando com o apoio da Academia Brasileira de Letras e da Liga da Defesa Nacional.

Entre os dirigentes da Liga Nacionalista, Frederico Vergueiro Steidel foi o mais comprometido com a manutenção dos vínculos com a figura de Olavo Bilac.

Em I9I7, durante uma sessão ordinária com a presença de Bilac, que passava pela cidade a serviço da LDN, Steidel propôs que o poeta fosse aclamado presidente honorário da instituição e obteve aprovação calorosa dos membros presentes ${ }^{\mathrm{T2}}$.

Valéria Medeiros chama atenção para a recorrente afirmação do laço umbilical entre o discurso de I9I5 e a Liga Nacionalista nas páginas de O Estado de São Paulo e também para a maior frequência com que isso ocorria nos textos assinados por Steidel. Segundo a autora, o jornal teria sido o principal veículo de divulgação da Liga Nacionalista, que diferentemente de outras agremiações do gênero não contava com um boletim ou revista própria ${ }^{\mathrm{T}}$.

Como era de se esperar, a morte de Bilac em 28 de dezembro de I9I8 causou comoção nacional. Em setembro de I9I9, a Câmara dos Deputados do Estado de São Paulo remetia ao Senado um projeto que contemplava a construção de um monumento em memória de Rodrigues Alves, presidente eleito pela segunda vez e morto em janeiro daquele ano antes da posse, e a abertura de um crédito de cinquenta contos de réis para auxiliar a construção de um monumento a Olavo Bilac ${ }^{\mathrm{I}}$.

Conforme o previsto, o montante serviria apenas para "auxiliar" a construção do monumento, sendo o restante arrecadado por Vergueiro Steidel através de uma intensa campanha para este fim. Segundo Bandecchi, foram distribuídas listas pela capital e no interior, autenticadas por Steidel, para receber donativos para

\footnotetext{
I2 BANDECCHI, Brasil. Liga Nacionalista. Cadernos de História, I4. São Paulo, Editora Parma, I980, p. 2I.

I3 MEDEIROS, Valéria Antônia, op. cit.

I4 CÂMARA DOS DEPUTADOS DO ESTADO DE SÃO PAULO. Projeto de Lei de Iniciativa da Câmara dos Deputados. I9I9. Acervo Histórico da Assembléia Legislativa do Estado de São Paulo. Disponível em <http:// goo.gl/JfiOQL〉. I7 abr. 20I4.
} 
o monumento. Com as contribuições, a obra foi encomendada ao escultor sueco William Zadig ${ }^{15}$.

O resultado foi um conjunto escultórico composto por cinco peças de bronze. A figura de Bilac, posta em uma tribuna em referência ao discurso na Faculdade de Direito, era a peça de maior dimensão e ficava no centro. As outras, ao redor, representavam quatro poemas: "A tarde", "O caçador de esmeraldas", "O beijo eterno" e "Pátria e família".

Alocado na Avenida Paulista, o monumento foi inaugurado em 7 de setembro de I922, em meio às intensas comemorações do Centenário da Independência. Francisco Pati relembra o acontecimento do qual participou enquanto estudante da Faculdade de Direito:

Lembro-me de que nos coube inaugurar, no fim da Avenida Paulista, [...] o monumento a Olavo Bilac. O orador oficial saiu do nosso meio. Sucedeu, porém, que o ato se revestiu de uma solenidade com a qual não contávamos. $O$ governo do Estado, tendo à frente o sr. Washington Luís, compareceu em peso. Compareceram também Dna. Cora Bilac Guimarães, saudosa irmã do excelso poeta, e seu marido, [...]. Armou-se no extremo daquela via pública, na esquina da rua Minas Gerais, um coreto para autoridades, convidados e comissão acadêmica, inclusive o orador.

Em toda a extensão da avenida, desde o 'Trianon' até o monumento, de lado a lado, soldados da Força Pública e alunos de escolas primárias e secundárias. Os convidados desciam do automóvel no 'Trianon' e faziam o resto do percurso a pé, de cabeça descoberta. Traje de rigor: fraque e cartola. Só obtinha ingresso no coreto quem estivesse de fraque e cartola. ${ }^{16}$

Uma fotografia, publicada no número especial da revista A Cigarra destinado à cobertura das festividades do Centenário em São Paulo, corrobora a presença de uma multidão presente ao ato de inauguração do monumento ${ }^{\mathrm{T}}$.

É também Francisco Pati quem recorda a reação da irmã do poeta à homenagem:

— Os senhores, paulistas, são os primeiros a lembrar-se de dar à imagem do meu irmão a perpetuidade do bronze. Com esse gesto, os senhores respondem às acusações de regionalismo intolerante. Bilac não nasceu em São Paulo, nasceu no Rio, mas é São Paulo que o consagra. Estou certa de que ele está contente lá onde se encontra. São Paulo era a sua fábrica de entusiasmo. ${ }^{\text {I8 }}$

Nada do que se fez no Rio de Janeiro até o final da década de I930 para celebrar a memória de Bilac se compara à homenagem da Liga Nacionalista. É certo que a Liga utilizou-se da feliz estratégia de fazer coincidir a inauguração do monumento

I5 BANDECCHI, Brasil, op. cit., p. 55 .

I6 PATI, Francisco, op. cit., p. 35 e 36.

I7 ASPECTO da Inauguração do Monumento ao Grande Poeta Nacionalista Olavo Bilac, na Avenida Paulista, em 7 de Setembro Último. A Cigarra, ano X, n.I93, I922. Disponível em <http://goo.gl/sfzhel〉. I5 abr. 20I4.

I8 PATI, Francisco, op. cit., p. I65. 
com as festividades do 7 de setembro de I922. Com isso associou sua homenagem àquela figura de forte apelo afetivo ao Centenário da Independência. Vale notar que a imprensa do Rio de Janeiro não deu qualquer atenção à inauguração do monumento, talvez por estar mais ocupada em cobrir os festejos do Centenário na capital.

Capitalizando o sucesso do evento, porém, semanas depois a Liga Nacionalista apresentava ao Senado do Estado de São Paulo uma representação, solicitando e sugerindo uma série de medidas que colocassem efetivamente em prática o regime instituído na Constituição. Tratava-se de mostrar a conveniência de uma série de práticas que garantissem o voto secreto e obrigatório, impedissem as fraudes e a corrupção eleitoral ${ }^{\mathrm{I}}$.

O imponente monumento sobreviveu pouco mais de uma década à Liga Nacionalista, extinta em I924 por suspeitas de envolvimento no levante revolucionário liderado por Isidoro Dias Lopes.

Em fevereiro de I935, o jornal A Gazeta anunciou a retirada do monumento a Olavo Bilac da Avenida Paulista, apresentando considerações que sugerem a existência de oposições à obra quase que desde a sua inauguração:

O prefeito, vivamente interessado na modernização da cidade, alargamento de ruas e praças, embelezamento de pontos, resolveu construir, na Avenida Paulista, onde está o monumento de Olavo Bilac, uma grandiosa esplanada que se projetará sobre o Pacaembu. [...] Mas para dar execução ao projeto, foi obrigado a sacrificar o monumento de Olavo Bilac, que será retirado da Avenida e colocado, talvez, no parque D. Pedro II. O gesto do prefeito Fabio Prado somente merece aplausos, pois que aquele trabalho de arte, não está mais à altura da educação artística de São Paulo. Já em I923, aqui, a mocidade acadêmica, com esta folha à frente, iniciou um movimento para retirada do monumento. E se não foi demolido, nesta ocasião, foi porque a polícia, prevenida, passou a vigiar o local. Agora, o prefeito Fabio Prado, além de introduzir grandes embelezamentos naquele ponto - presta, a São Paulo artístico, um inestimável serviço, removendo o monumento dali. ${ }^{20}$

Desmontadas e guardadas num depósito da prefeitura, foi somente décadas mais tarde que algumas peças do monumento voltaram a ocupar separadamente espaços públicos da cidade de São Paulo.

A memória de Bilac, entretanto, iria sofrer uma importante inflexão em I939. Se, até então, havia sido cultuada predominantemente por instituições e indivíduos aos quais o poeta esteve associado em vida, o Decreto-lei n. I.908 de 26 de dezembro, ao mesmo tempo em que homenageava nacionalmente o poeta, transformando sua data de nascimento, I6 de dezembro, em Dia do Reservista, a fim de promover o alistamento no contexto da Segunda Guerra Mundial, conferia novo sentido à campanha de Bilac, associando-a à cooptação de soldados pelo Estado autoritário ${ }^{21}$.

I9 LIGA NACIONALISTA. Representação. I922. Disponível em 〈http://goo.gl/2MBdqS〉. I7 abr. 2014 .

20 NOTÍCIA sobre a Retirada do Monumento à Olavo Bilac. A Gazeta, São Paulo, 2 jul. I935.

2I DECRETO-LEI n. I.908, I939. Disponível em <http://goo.gl/tJyPb2〉. I6 abr. 20I4. 
Dezembro de 1939 foi marcado por uma intensa agenda de comemorações organizadas pela Comissão Nacional de Homenagem à Memória de Bilac, encabeçada por Eurico Gaspar Dutra, ministro da guerra, com larga divulgação e cobertura nos periódicos.

Em paralelo, a imprensa registrou também a ocorrência de homenagens espontâneas e oportunistas, ou seja, não previstas pela agenda da Comissão, tanto na capital como em várias outras cidades do país. Em São Paulo, por exemplo, no dia 27 de dezembro a Folha da Manhã informava a adesão do interventor Adhemar de Barros às solenidades promovendo uma série de eventos. Destaco a afixação de uma placa de bronze na Faculdade de Direito com a seguinte inscrição: "A Olavo Bilac, no momento em que a Pátria começa a colher os frutos das sementes que ele plantou nesta Faculdade, O Governo do Estado de São Paulo, São Paulo, XXVII-XII-MCMXXXIX”, a qual, pode-se dizer, reivindicava a primazia paulista para esta nova narrativa da memória de Bilac que se integrava à memória nacional ${ }^{22}$.

Na capital, a adesão do presidente Getúlio Vargas ao programa proposto e iniciado pelos membros militares do governo se deu com algum atraso. Somente em meio ao calendário de comemorações, no decorrer da extensa programação e após um "convite" pessoal dos membros da Comissão que teriam ido ao Palácio do Catete com esta finalidade, o presidente acabou por comparecer à solenidade no Colégio Militar, onde foi inaugurada a "Alegoria a Bilac" e organizada uma exposição com os objetos pessoais do poeta. A adesão do presidente conferiu maior importância e visibilidade aos eventos comemorativos que eram, contudo, resultado da iniciativa dos militares.

Convenientemente, o culto à memória do amado poeta civil que defendeu o serviço militar obrigatório começava, naquele momento, a adquirir o sentido de uma união entre civis e militares.

É significativo, porém, que em meio a uma profusão de notícias sobre as homenagens a Bilac, um interesse sobre aspectos da vida do poeta não relacionados ao seu patriotismo, como a boêmia, a produção de versos eróticos e satíricos, o noivado desfeito, tenha encontrado expressão em artigos de jornais e revistas durante as décadas de I940 e I950. Os títulos sugerem o forte apelo popular de sua figura e a contribuição de outros atores para a construção de uma memória que se compunha também de ingredientes extraoficiais. Cito como exemplos: "A noiva de Bilac" (I943); "Bilac amou na vida" (I95I); "Olavo Bilac, estudante em São Paulo" (I94I); "Bilac viveu ou imaginou o seu erotismo?" (I94I); "Meu encontro com Bilac" (I94I); "A noiva de Bilac” (I95I); “Uma família de poetas” (I94I); “D. Amélia Mariano de Oliveira” (I945); "Os poetas Bilac, Alberto e Raimundo andaram seriamente brigados: anos depois se reconciliaram" (I950); "O grande amor que iluminou a vida do poeta" (I936); “Uma resposta de Bilac e outras curiosidades" (I942); "Episódios inéditos e pitorescos na vida de Bilac" (I94I) ${ }^{23}$.

Títulos de livros sobre Bilac publicados até o golpe de I964 também demonstram o maior interesse dos biógrafos na fase boêmia e em aspectos íntimos da vida do poeta,

22 HOMENAGENS à Memória de Olavo Bilac. Folha da Manhã, São Paulo, 27 de dezembro de I939, Arquivo da Folha de São Paulo. Disponível em 〈http://goo.gl/KKfwrN〉. I6 abr. 20I4.

23 BUENO, Alexei. Bibliografia. In: (ed.). Olavo Bilac. Obra Reunida. Rio de Janeiro, Editora Nova Aguilar, I996. p. I060 e I06I. 
por exemplo: A vida exuberante de Olavo Bilac (I944) e Olavo Bilac — bom humor (s.d.) de Elói Pontes; Bilac, vida e obra de Henrique A. Orciuoli (I94I); Olavo Bilac (sua vida e suas obras) (I943) de Álvaro Guerra; O noivado de Bilac de Elmo Elton (I954); A boêmia do meu tempo, no qual Bilac é um dos protagonistas, de Leôncio Correia (I955); Olavo Bilac. O homem e o amigo de Nelson Líbero (I960); e Vida e Poesia e Olavo Bilac (I963, I965, I972, I977, I99I, I992, 2007) de Fernando Jorge.

Em contrapartida, é durante o regime militar que a vida de Bilac começa a aparecer representada em títulos mais sérios: Olavo Bilac e o serviço militar obrigatório, $o$ homem, o artista, o patriota (I969); Olavo Bilac, o homem cívico (I968); Bilac e o serviço militar (I966); Olavo Brás Martins dos Guimarães Bilac, príncipe dos poetas brasileiros, patrono do serviço militar (I974).

Vale notar que a imprensa do período pouco publicou sobre Bilac, em contraste com as décadas anteriores. Tal silêncio, significativo, pode sugerir uma resistência ao evidente uso político da imagem de Bilac nos trabalhos de enquadramento de sua memória empreendidos pela Ditadura ${ }^{24}$.

Uma polêmica em torno da primeira edição do livro de Fernando Jorge, relatada pelo autor no prefácio à $2^{\mathrm{a}}$ edição e reproduzida em edições posteriores, é eloquente sobre o policiamento das narrativas da vida do poeta, que se ia transformando em herói das Forças Armadas pouco após a tomada do poder.

Vida e poesia de Olavo Bilac, publicado pela primeira vez em I963, foi a biografia mais bem-sucedida de Bilac do ponto de vista comercial. A levar em conta o relato de Fernando Jorge, tal sucesso naquele momento poderia inclusive estar relacionado à polêmica que suscitou. De acordo com o biógrafo, seu livro teria provocado reações indignadas de parentes e críticos, entre os quais sobressaem os acadêmicos Raimundo Magalhães Júnior e Austregésilo de Athayde. O primeiro, autor de uma biografia de Bilac publicada anos depois. O segundo, o presidente da Academia Brasileira de Letras com maior tempo de permanência no cargo, era também membro ativo da Liga da Defesa Nacional e foi o representante da ABL na comissão para as comemorações do centenário de Olavo Bilac, instituída pelo governo militar em I965.

Nas palavras de Jorge:

O acadêmico R. Magalhães Júnior [...] em vez de realizar uma análise honesta, imparcial, caiu no destampatório, começou a urrar, a investir às tontas, e isto numa tediosa e longa moxinifada. Irritou-se sobremaneira, o fracassado biógrafo de Cruz e Sousa, com a descrição que fizemos da existência boêmia de Olavo:

'Lendo tal livro, tem o leitor a impressão de que Bilac era um sujeitinho gracejador e irresponsável, pertencente a uma súcia de gaiatos mais ou menos desocupados, que levavam a vida entre brejeirices e anedotas, pregando peças a Deus e ao mundo.'

E aludindo às nossas inocentes indiscrições, [...] sentenciou: — 'Bilac é intocável. Está morto e não pode defender-se.'

24 Sobre práticas de "enquadramento da memória” ver POLLAK, Michael. Memória, Esquecimento, Silêncio. Revista Estudos Históricos, Rio de Janeiro, n.2, p. 3-I5, I989. 
Íamos acolhendo todos esses comentários com um misto de espanto e curiosidade: até onde os acusadores pretendiam chegar? O nosso pasmo atingiu o auge quando soubemos, pela imprensa, que o escritor Austregésilo de Athayde, Presidente da Academia Brasileira de Letras, tencionava convocar uma reunião, a fim e deliberar sobre as medidas que a Casa de Machado de Assis deveria adotar para a defesa da memória do sonetista de 'Ouvir Estrelas'.

— 'Não é admissível que Bilac — declarou o Presidente da Academia - uma personalidade tão rica de humanidade e de vida, um poeta da sua grandeza e significação, seja apresentado ao público apenas no seu aspecto menos simpático e tantas vezes depreciativo, como no citado livro.'

Secundando o Sr. Austregésilo de Athayde, a Liga de Defesa Nacional, que tem em Olavo Bilac um os seus patronos, também ameaçou de formular um protesto.

A esta altura, no meio de tamanha celeuma, o livro transformou-se num 'best-seller', sendo colocado na lista dos mais vendidos em todo o país, conforme o resultado de uma pesquisa feita pelo jornal 'O Globo'.25

Numa época de acirrada polarização ideológica e busca de legitimação para as ações militares na contínua aprovação e colaboração da sociedade civil com a intervenção militar, a polêmica demonstra a existência de aspectos desejáveis e indesejáveis na imagem de Bilac.

Em meados dos anos I960, tempos de grande mobilização de setores conservadores em defesa de valores tradicionais de família e religião, não surpreende que a moral de um herói da pátria fosse objeto de vigilância e preocupação. Faz sentido, pois, a indignação com a divulgação de aspectos da vida de Bilac que poderiam pôr em causa a simpatia pelo defensor intransigente do serviço militar obrigatório, que em I966 veio a ser o primeiro civil dentre os patronos das forças armadas. Em suas virtudes, Bilac era o ícone perfeito para o momento, capaz de simbolizar a conciliação entre civis e militares em prol da pátria. Como boêmio, porém, ameaçava valores morais caros aos militares e aos segmentos que os apoiavam.

Em I7 de agosto de I965, Castello Branco e seu ministro da Educação e Cultura, Flavio Lacerda, assinaram o Decreto n. 56.742 que dispunha sobre a formação de uma comissão para organizar as solenidades comemorativas do centenário de nascimento de Olavo Bilac,

[...] autor da letra do Hino à Bandeira, propugnador do serviço militar obrigatório e grande incrementador do sentimento do civismo, que deve ser incutido na juventude. [...]

CONSIDERANDO que o sentimento do dever cívico se inspira nos grandes momentos em que a Pátria tem a oportunidade de rememorar os seus vultos maiores, avivandolhes os feitos na memória dos contemporâneos e retirando nos exemplos do passado também a lição para as gerações mais novas, [...]. ${ }^{26}$

25 JORGE, Fernando. Prefácio à 2a. Edição. In: Vida e poesia de Olavo Bilac. 3.ed. São Paulo, McGraw Hill, I977.

26 DECRETO n. 56.742. In: Bilac, Olavo, A Defesa Nacional, op. cit., I965, p. I9-20. 
A comissão, reunida e anunciada em seguida pela Portaria n. 258, tinha como principal tarefa "elaborar o plano das solenidades comemorativas do centenário do nascimento de Olavo Bilac, [...] promovendo os atos cívicos, culturais e educativos destinados a dignificar e avivar, na memória dos contemporâneos, a trajetória terrena do insigne poeta e homem público". Os seguintes nomes a constituíram: Raymundo Moniz Aragão, Diretor do Ensino Superior; Almirante Álvaro Alberto da Motta e Silva, presidente da Liga da Defesa Nacional; Austregésilo de Athayde, presidente da Academia Brasileira de Letras; tenente-coronel João de Souza Carvalho, representante do Ministério da Guerra; capitão de corveta Carlos Miguez Garrido, representante do Ministério da Marinha; capitão-aviador Hélio Paes de Barros, representante do Ministério da Aeronáutica; e José Pedro Ferreira da Costa, sub-chefe do gabinete do ministro da Educação e Cultura ${ }^{27}$.

Entre as atividades da comissão, destaco a reedição do livro A Defesa Nacional, publicado pela primeira vez em I9I7 pela Liga da Defesa Nacional e sem outra reedição até $1965^{28}$.

A Defesa Nacional, edição da Comissão de Comemoração do I Centenário de Nascimento de Olavo Bilac, assim como a primeira edição da Liga, consiste numa coletânea de discursos proferidos entre I9I5 e I9I7, apresentados em ordem cronológica, com a novidade do acréscimo de quatro textos: "Apresentação ; O que significa este livro ; Decreto n. 56.742 [...] sobre as solenidades comemorativas do centenário de nascimento de Olavo Bilac; ; a Portaria n. 258 que indicava os nomes da comissão.

Na Apresentação, assinada por todos os membros, explica-se que:

[a Comissão,] diante da magnitude da tarefa imposta e da exiguidade do tempo para desempenhá-la condignamente, [...] pode verificar que a iniciativa de promover, em esmerada edição crítica, a publicação das Obras Completas de Olavo Bilac [...] constituiria a homenagem mais adequada e duradoura [...], mas que esse intento se deteve frente a intransponíveis obstáculos de ordem legal, sem embargo do entusiasmo que suscitou e da cooperação que mereceu. ${ }^{29}$

A intenção de uma obra completa jamais seria concretizada. No que diz respeito ao volume de A Defesa Nacional, embora todos os textos adicionados à edição de 1965 contribuam de alguma maneira para a produção de novas leituras das palavras de Bilac, o mais interessante é, sem dúvida, o de Carlos Maul, intitulado "O que significa este livro”. Este, pode-se dizer, traduz claramente a direção assumida pela operação de enquadramento da memória de Bilac durante a ditadura.

Maul, que chegou a conhecer o poeta por volta de I9Io e participou das comemorações de I939, começa seu texto apresentando duas razões pelas quais se impunha aquela reedição:

\footnotetext{
27 PORTARIA n. 258. In: BILAC, Olavo, op. cit., I965, p. 2I.

28 Os discursos, entretanto, foram inseridos no volume póstumo BILAC, Olavo. Últimas Conferências e Discursos. Rio de Janeiro, Livraria Francisco Alves, s.d.
}

29 ARAGÃO, Raymundo et al. Apresentação. In: BILAC, Olavo, A Defesa Nacional, op. cit., I965, p. Io. 
[...] a primeira com sentido de reverência ao Poeta da Pátria, na data do centenário de seu nascimento, e a segunda pelo cunho de atualidade que transcende do que em I9I5 proclamou ao Brasil inteiro o que ele precisava ouvir, numa hora de angústia e de perplexidades, para compreender a necessidade de sua defesa e a opção por um destino. ${ }^{\circ}$

Ambas as razões se entrecruzam nos argumentos apresentados nas páginas seguintes, os quais descontextualizam os discursos atribuindo-lhes "atualidade" e "transcendência", ao mesmo tempo em que lhes conferem novo significado no contexto de sua reedição em I965, segundo ano do governo militar, como aliás indica o próprio título.

É importante destacar a presença de palavras-chave do vocabulário político do período e seu uso em associações semânticas próprias aos discursos em defesa do golpe e do regime. Por este artifício, Carlos Maul definia com as cores da ditadura termos e conceitos como revolução, liberdade e democracia, por exemplo, alguns absolutamente estranhos aos discursos de Bilac.

Nas palavras de Maul:

Tomado o vocábulo na sua justa acepção semântica, o que o nosso admirável patrício promoveu com o seu verbo maravilhoso, foi uma revolução, porque revolução não é a força cega das massas que se autodestroem [...], mas uma afirmação de vontade que renova, que constrói para um futuro de grandeza, oposto ao que só nos dava inferioridade e desprestígio no mundo. Assim, pacificamente, Olavo Bilac desfraldou a bandeira da reestruturação da arquitetura social e política do país, sobre alicerces eternos, [...]

[...] em menos de dois anos, o Exército deixava de ser um castigo para transformar-se no núcleo em que formariam o caráter, a mentalidade de um Brasil renovado e com a compreensão de que a liberdade só deixa de ser um mito quando se ergue uma força material que a sustente em plenitude.

[...]

Cinquenta anos passaram. Acontecimentos vários surgiram. O Brasil revelou-se esclarecido e desperto para as atividades reclamadas para o seu progresso. [...] E os rumos quem os traçava nessas ocasiões era o Exército, o elemento aglutinante por excelência, o reservatório de almas para a democracia a que Bilac se referira com ênfase no seu apostolado. Do mérito desse ímpeto revolucionário que se manifestara em I9I5, o presente nos oferece uma prova concreta na Revolução de 3I de março de I964. ${ }^{\text {I }}$

É curiosa a noção de tempo subjacente a essa explicação de Maul para a revolução de Bilac, dada por concluída somente cinquenta anos depois. Também a afirmação de que Bilac se "referira com ênfase" à democracia durante sua campanha e à ideia do Exército como um "reservatório de almas" para um regime democrático. Os contrastes e contradições com os discursos que seguem são patentes para o leitor capaz de identificar os diferentes contextos inscritos nas duas edições. Por exemplo:

30 MAUL, Carlos. O Que Significa Este Livro. In: BILAC, Olavo, op. cit., I965, p. I3.

3I Idem, p. I4-I6. 
como falar em ênfase se a palavra democracia aparece apenas duas vezes nos dezoito discursos de Bilac, nomeadamente nos discursos “Em Marcha!” e em "A Defesa Nacional"?

No primeiro a palavra aparece inscrita no seguinte parágrafo:

[...] Que é o serviço militar generalizado? É o triunfo completo da democracia; o nivelamento das classes; a escola da ordem, da disciplina, da coesão; o laboratório da dignidade própria e do patriotismo. É a instrução primária obrigatória; é a educação cívica obrigatória; é o asseio obrigatório, a higiene obrigatória, a regeneração muscular e psíquica obrigatória.32

Já em “A Defesa Nacional”, conferência realizada em várias cidades e último texto do livro, Bilac afirma:

É inconcebível a vitória de uma democracia sem a instrução da massa pública. Estabelecemos a República; mas pode viver dignamente uma República, uma pátria republicana, quando a maior parte dos seus filhos seja de analfabetos, e, portanto de inconscientes?33

Note-se a contiguidade entre os conceitos de democracia e república. Na concepção de Bilac, e para a maioria dos contemporâneos, república e democracia opunham-se à monarquia, escravidão, aristocracia e outras formas de distinção social que não resultassem da meritocracia. Seu elemento fundamental era a fraternidade, único possível para a coesão nacional. É neste sentido que as propostas de Bilac apontam, além da instrução pública, para o serviço militar obrigatório como uma "escola de nacionalidade", onde jovens de diversas origens tornam-se irmãos em armas tal como na eloquente e conhecida metáfora. Paralelamente, a amizade fraternal, um dos principais topoi da literatura cívico-pedagógica, é o meio que o autor escolhe em sua obra de ficção infantil para a resolução dos conflitos gerados pelas diferenças de cor, renda, escolaridade e origem social das suas personagens. Feitas a Abolição e a Proclamação da República, sem as necessárias medidas para corrigir as desigualdades estabelecidas, mantidas sob variadas formas, e sem cessar de produzir outras formas e mecanismos de diferença e distinção social, a fraternidade foi sempre um aspecto controverso e problemático nas narrativas da identidade nacional brasileira34.

Em contrapartida, no texto de Carlos Maul a palavra república não aparece uma só vez. Está claro que o conceito já não tinha a mesma relevância no vocabulário político dos anos I960 e que naquele contexto o comunismo tornara-se o oposto conceitual

32 BILAC, Olavo, A Defesa Nacional, op. cit., I965, p. 26 e 27.

33 Idem, p. I36.

34 A respeito da literatura cívico-pedagógica republicana ver: HANSEN, Patrícia Santos. Cap. 2-A arte de formar brasileiros. In: . Brasil, um país novo: literatura cívico-pedagógica e a construção de um ideal de infância brasileira na Primeira República. Tese de doutorado em História Social. São Paulo, Faculdade de Filosofia, Letras e Ciências Humanas, Universidade de São Paulo. Disponível em <http://goo.gl/xNZkjj>. $I^{0}$ dez. 20I4. 
de democracia. Ao mesmo tempo, militares e grupos apoiantes apropriavam-se da palavra revolução e de seu significado. Destarte, o que era democrático ou republicano para Bilac, a igualdade dos cidadãos no serviço militar obrigatório, aparece na releitura de Maul como o ponto de partida de uma campanha cujo êxito maior teria sido a transformação dos militares em um grupo social dotado de extraordinária autoridade moral pela sua lealdade à pátria, que agora era incumbido da missão de salvaguardar a "democracia" da "ameaça estrangeira" do comunismo35.

O salto associativo de I9I5 a I965 merece uma leitura atenta:

Tudo como que indicava que olvidáramos os ensinamentos do mestre. Deformava-se o espírito do regime, as instituições políticas eram solapadas pelas correntes subterrâneas, [...] O comunismo anunciava o seu próximo advento. Afirmavam ter em suas mãos o governo, faltando-lhe vencer a última etapa, que seria a tomada do poder. [...] isso não era o povo, não era a nossa gente, eram bandos de apátridas que repetiam ordens de comando vindas do estrangeiro. E quando os fatos definiram uma situação intolerável, saíram à rua os brasileiros autênticos de todas as classes, unidos por um só pensamento, o da restauração da ordem conspurcada e o da expulsão dos invasores. De norte a sul, homens e mulheres tomaram posição nas linhas de vanguarda e voltaramse para os quartéis inatingidos pelo veneno das ideologias antinacionais e corrosivas. E quem vivia nas casernas, sob a influência os ensinamentos redentores, das lições do patriotismo disseminadas pelo Poeta? [...] As reservas que aí haviam feito o seu aprendizado, espalhavam-se pelo Brasil afora e nas fileiras os novos conscritos, no ato do juramento sagrado, cantavam o mesmo Hino à Bandeira que aprenderam na infância nas escolas primárias. Esse Hino era de Olavo Bilac.

Foram esses batalhões que obedeceram ao Alto Comando que lhes mostrou o caminho iluminado na madrugada de 3I de março de I964. ${ }^{36}$

Nas páginas seguintes, as palavras de ação proferidas meio século antes resistem ao sentido profético que lhes foi atribuído a posteriori. O significado do livro era imposto ao leitor; porém, na concepção de Bilac, o êxito do serviço militar obrigatório seria o de promover a cidadania e criar condições para a república democrática. Isso, acreditava, seria o maior obstáculo a uma intervenção militar. Em suas palavras:

Todos têm medo do militarismo no sentido da preponderância da classe militar, na significação do despotismo militar. Tenho também medo disso e mais do que medo: profundo horror e profunda aversão. Mas as condições essenciais para a existência de qualquer despotismo são a ignorância e a indiferença da massa do povo. Não há povo nenhum, instruído, cívica e militarmente instruído, que suporte qualquer despotismo.37

35 A batalha conceitual e semântica por trás das denominações dos eventos, ações, sujeitos e períodos concernentes ao golpe de I964, incluindo o tempo anterior ao golpe e o do regime subsequente, é um aspecto essencial do debate que atravessa a historiografia sobre o período. Conferir, entre outros: FICO, Carlos. Versões e Controvérsias sobre I964 e a Ditadura Militar, Revista Brasileira de História, n.24, p. 29-60, 2004. 36 MAUL, Carlos, op. cit. p. I6-I8.

37 BILAC, Olavo, A Defesa Nacional, op. cit., I965. p. I65-I40. 
Ironicamente, foi por determinação da ditadura militar que Bilac alcançou o panteão dos heróis nacionais pela defesa de sua causa mais cara: a do serviço militar universal como condição de cidadania e obstáculo à intervenção política das "classes militares".

O fim dessa história, conforme o decreto citado no início do trabalho, já se sabe. Após as comemorações do Centenário, Castello Branco e seus ministros fariam de Bilac o primeiro civil entre os patronos das Forças Armadas. Como no Estado Novo, mas com efeitos mais perversos e duradouros, a imagem e as ideias do poeta, que defendeu a aplicação da lei do sorteio militar para todos os brasileiros como condição de uma nação republicana e democrática, adaptaram-se na memória social aos esforços de uma aliança entre interesses civis e militares para legitimação de um governo autoritário.

\section{SOBRE A AUTORA}

PATRÍ́cIA SANTOS HANSEN doutora em História Social da Cultura pela Universidade de São Paulo (FFLCH-USP, 2007). Realizou pós-doutorado no Centro de Pesquisa e Documentação em História Contemporânea do Brasil (CPDOC-FGV) com o apoio do Programa Nacional de Apoio ao Pós-Doutorado da Capes/FAPERJ. Foi Marie Curie Fellow, atuando como investigadora da área de História de Educação do Instituto de Educação da Universidade de Lisboa pelo programa Welcome II, entre 20II e 20I4. Atualmente é investigadora visitante do ICS-UL com Bolsa de Cientista Convidado da Fundação para a Ciência e Tecnologia de Portugal. E-mail: hansenwagner@gmail.com

\section{REFERÊNCIAS BIBLIOGRÁFICAS}

ARAGÃO, Raymundo et al. Apresentação. In: BILAC, Olavo. A Defesa Nacional. Edição da Comissão de Comemoração do I Centenário de Nascimento de Olavo Bilac. Rio de Janeiro, Biblioteca do Exército Editora, I965.

ASPECTO da Inauguração do Monumento ao Grande Poeta Nacionalista Olavo Bilac, na Avenida Paulista, em 7 de Setembro Último. A Cigarra, ano X, n.I93, I922. Disponível em <http://goo.gl/ sfzhel>. I5 abr. 20I4.

BANDECCHI, Brasil. Liga Nacionalista. Cadernos de História, I4. São Paulo, Editora Parma, I980.

BILAC, Olavo. A Defesa Nacional. Rio de Janeiro, Liga da Defesa Nacional, I9I7. Disponível em <http:// goo.gl/RsRn7m>. I6 de abr. 20I4.

BILAC, Olavo. A Defesa Nacional. Edição da Comissão de Comemoração do I Centenário de Nascimento de Olavo Bilac. Rio de Janeiro, Biblioteca do Exército Editora, I965. 
BILAC, Olavo. Últimas Conferências e Discursos. Rio de Janeiro, Livraria Francisco Alves, s.d..

BUENO, Alexei. Nota Editorial. In: . (ed.). Olavo Bilac. Obra Reunida. Rio de Janeiro, Editora Nova Aguilar, I996. . Introdução Geral. In: . (ed.). Olavo Bilac. Obra Reunida. Rio de Janeiro, Editora Nova Aguilar, I996. . Bibliografia. In: (ed.). Olavo Bilac. Obra Reunida. Rio de Janeiro, Editora Nova Aguilar, I996. CÂMARA DOS DEPUTADOS DO ESTADO DE SÃO PAULO. Projeto de Lei de Iniciativa da Câmara dos Deputados. I9I9. Acervo Histórico da Assembleia Legislativa do Estado de São Paulo. Disponível em <http://goo.gl/JfiOQL >. I7 abr. 20I4.

CIGARROS BILAC. A Cigarra, Anno III, n.52, I9I6. Disponível em 〈http://goo.gl/FJWk6Z〉. I5 abr. 2014. DECRETO-LEI n. I.908, I939. Disponível em <http://goo.gl/tJyPb2〉. I6 abr. 2014.

DECRETO n. 56.742. In: Bilac, Olavo. A Defesa Nacional. Edição da Comissão de Comemoração do I Centenário de Nascimento de Olavo Bilac. Rio de Janeiro, Biblioteca do Exército Editora, I965, p. I9-20. DECRETO n. 58.222, de I9 de abril de I966. Disponível em 〈http://goo.gl/OjceMS〉. 5 mar. 2014.

DIMAS, Antônio (org.). Bilac, o jornalista. São Paulo, EDUSP/Imprensa Oficial; Campinas, Editora Unicamp, 2006.

FICO, Carlos. Versões e Controvérsias sobre I964 e a Ditadura Militar. Revista Brasileira de História, n.24, p. 29-60, 2004. Disponível em <DOI: IO.I590/SoIO2-0I882004000IO0003〉. 7 abr. 2015.

FON-FON, 20 de outubro de I9I5. Disponível em 〈http://goo.gl/NrhBzt $\rangle$. I6 abr. 2014.

HANSEN, Patrícia Santos. Brasil, um país novo: literatura cívico-pedagógica e a construção de um ideal de infância brasileira na Primeira República. Tese de doutorado em História Social. São Paulo, Faculdade de Filosofia, Letras e Ciências Humanas, Universidade de São Paulo. Disponível em <http://goo.gl/xNZkjij. I I dez. 20I4.

HOMENAGENS à Memória de Olavo Bilac. Folha da Manhã, São Paulo, 27 de dezembro de I939, Arquivo da Folha de São Paulo. Disponível em 〈http://goo.gl/KKfwrN〉. I6 abr. 2014.

JORGE, Fernando. Prefácio à 2a. Edição. In: . Vida e poesia de Olavo Bilac. 3.ed., São Paulo, McGraw Hill, I977.

LIGA NACIONALISTA. Representação. I922. Disponível em 〈http://goo.gl/2MBdqS〉. I7 abr. 2014.

MAUL, Carlos. O Que Significa Este Livro. In: BILAC, Olavo. A Defesa Nacional. Edição da Comissão de Comemoração do I Centenário de Nascimento de Olavo Bilac. Rio de Janeiro, Biblioteca do Exército Editora, I965.

MEDEIROS, Valéria Antônia. Antonio de Sampaio Dória e a Modernização do Ensino em São Paulo nas

Primeiras Décadas do Século XX. Tese de doutorado em História da Educação. São Paulo, Pontifícia Universidade Católica de São Paulo, 2005. Disponível em <http://goo.gl/4FdLHI〉. I5 abr. 2014.

NOTÍCIA sobre a Retirada do Monumento à Olavo Bilac. A Gazeta, São Paulo, 2 jul. I935. Arquivo Olavo Bilac. Centro de Memória da Academia Brasileira de Letras.

PATI, Francisco. O Espírito Das Arcadas. São Paulo, Associação dos Antigos Alunos da Faculdade de Direito de São Paulo, 2008. Disponível em <http://goo.gl/Hci3Cz〉. I6 abr. 20I4.

POLLAK, Michael. Memória, Esquecimento, Silêncio. Revista Estudos Históricos, Rio de Janeiro, n.2, p. 3-I5, I989.

PORTARIA n. 258. In: BILAC, Olavo. A Defesa Nacional. Edição da Comissão de Comemoração do I Centenário de Nascimento de Olavo Bilac. Rio de Janeiro, Biblioteca do Exército Editora, I965. SOUZA FILHO, Danilo Marcondes de. A teoria dos atos de fala como concepção pragmática de linguagem. Filosofia Unisinos, n. 7, p. 2I7-30, 2006. 